rigorously orthodox Lamarckians or Darwinians among biologists. Little by little, just as modern houses are built with the ruins of ancient temples, an edifice has risen out of the crumbling theories of Lamarck and Cope, of Darwin and Wallace, of Eimer and Weismann -an interpretation of evolution which retains the tested facts of all previous attempts at a general explanation and which, with no pretense of finality, keeps the unbridged gaps well in view. Seven years ago, I wrote for the Revue an article $^{2}$ in which this theory was anonymously set forth and I find it needs very little modification at the present time. According to this theory, the unforeseen modifications of the germ plasm-whether called mutations or sudden or discontinuous variations-produced at a last analysis by environmental changes, are the source of the morphological and physiological differences that distinguish one definite species from another. This, as will be readily seen, is neither Lamarckism nor Darwinism. Natural selection controls development in animals and in plants by the elimination of the individuals and species not adapted to survive under given conditions, a selection which permits only the "fit" to exist. The adaptations indispensable for life in given surroundings must therefore precede chronologically these environmental conditions and they are not determined by the conditions to which they seem to correspond with such nicety. Herein lies the most original point of the theory and one that will, no doubt, meet with the greatest opposition. I prefer not to dwell upon it here but shall defer its demonstration to a later time.

THE FILLING OF UNOCCUPIED PLACES IN NATURE AND THE ORIGIN OF ADAPTATIONS ${ }^{3}$

IN the theory of the survival of adaptive mutations, as set forth above, neither Lamarckian factors nor the selection of minute

${ }^{2}$ L. Cuénot, "L'évolution des théories transformistes," Revue générale des Sciences, t. XII., p. 264, 30 mars, 1901.

${ }^{3}$ Cuénot, L., 1909, "Le Peuplement des Places Vides dans la Nature et l'Origine des Adaptations." Translated from Rev. gén. Sci. pures et appliq., Ann. 20, no. 1, 15 janvier, 1909. variations determines the appearance of new characters. The mutations occur fortuitously as continuous or discontinuous, the result of modifications in the germ plasm. If by chance the variant, such as it is or by some change of function, is adapted to fill a void in nature and is able to reach this unoccupied place, it has the opportunity to survive and to found a new stock; if not, it remains in its original surroundings or disappears. Formerly, when unoccupied places were more abundant, in fresh water, in marshes, in cracks and caverns and on the earth's surface, in the air, in the polar regions, conditions were favorable to the differentiation of new species and new groups; now mutations have an ever-decreasing chance of finding an occupied place in the fine balance of life already established, and evolution, if not entirely checked, has at least become much retarded.

SPECIAL ARTICLES

THE QUESTION OF VIVIPARITY IN FUNDULUS MAJALIS

IN a paper dealing with the process of heredity in Fundulus hybrids ${ }^{1}$ certain well-marked differences were shown by the writer to exist between the two reciprocal crosses. While a large per cent. of the hybrids, obtained by fertilizing the eggs of Fundulus heteroclitus with the sperm of $F$. majalis, hatched and, in some cases, throve for months after hatching, the embryos of the reciprocal cross ( $F$. majalis eggs fertilized with $F$. heteroclitus sperm) developed well for about two weeks and then ceased to grow. These embryos developed from the larger eggs of the larger species, yet reached a maximum size only equal, on the average, to that of the just hatched young fish of the smaller species, $F$. heteroclitus. Although morphologically sufficiently advanced, they never hatch, but remain stranded on a large yolk mass which they seem incapable of assimilating.

These and other peculiarities of cross-bred

1 "The Process of Heredity as Exhibited in the Development of Fundulus Hybrids," Journal of Experimental Zoology, Vol. V., No. 4. 
$F$. majalis embryos were dealt with by the writer as physiological conditions resulting from an incompatibility of the germinal materials involved, and furnished the basis for the discussion of a number of general questions. It was, then, somewhat of a shock to learn through the kindness of Dr. H. D. Senior, of the Syracuse University Medical School, that the well-known ichthyologist, John A. Ryder, had in 1885 described Fundulus majalis as a viviparous species. If Ryder's statement were correct it would be necessary completely to revise all statements made by the present writer that were based on the assumption that the species in question is strictly oviparous. The failure to hatch, for example, might be due to abnormal environment.

In the paper referred to ${ }^{2}$ Ryder, after dealing with certain well-authenticated cases of viviparity among the Pœcilliidæ, describes in a final paragraph (p. 155), under the heading "The Viviparity of Fundulus," another type of viviparous embryo, differing from Gambusia in having a distinct zona. The vitelline circulation is described and several points of similarity between Fundulus and Gambusia are noted.

On Plate XI., figs. 29 and 30, are pictured two rather advanced embryos of Fundulus majalis, described in the legend as having been "forced from the ovary by pressing the abdomen of the living fish." These figures bear a general resemblance to the corresponding stages of the $F$. majalis embryos studied by the writer, but might readily represent those of some other species. The thick gelatinous envelope characteristic of the extruded eggs of $F$. majalis is omitted in the figures.

During the past summer the opportunity was offered for thoroughly testing the question of viviparity in this species, and the results of the test force the conviction that Fundulus majalis, as it occurs at Woods Hole, Mass., is strictly oviparous and that the conclusions expressed by the writer in the paper

2 "On the Development of Osseous Fishes," Proceedings of the United States National Museum, Vol. VIII., No. 9. on Fundulus hybrids are founded on no misconception regarding the normal mode of gestation of the $F$. majalis embryos.

The following are the considerations that have forced this conviction:

1. Literally thousands of females of this species have been stripped by the writer and by many other students and investigators during the past decade, and no one has ever reported the extrusion of an egg containing an embryo.

2. This summer many females were opened at all stages of the breeding season. In no case were embryos found.

3. The number of eggs extruded at one time by a single female may run from 200 to 800. This number is far in excess of that which could possibly develop within the mother. It is well known, moreover, that viviparous species, whether with ovarian or oral gestation, have small numbers of eggs, usually not over 25 to 50 .

4. The eggs are provided with a thick, somewhat fibrous, gelatinous coat, that causes them to adhere, after extrusion, to objects on the bottom. The function of such an envelope could scarcely be conjectured on the assumption that the species is viviparous.

5. A study of the spawning behavior of $F$. majalis has shown that, at least in captivity, the eggs are extruded during the spawning act and are fertilized externally by one or by several males.

6. The anal fin, which, in truly viviparous species like Gambusia, is modified into a stiff, pointed intromittent organ, is, in $F$. majalis, soft, blunt and in no way adapted for intromission.

7. Several masses of normally developing $F$. majalis eggs were found in the sand at low tide, closely associated with the eggs of Limulus. These eggs were identified as belonging to the species mentioned by several investigators at the Woods Hole laboratories.

There appears, then, to be a marked discrepancy between Ryder's statement and the facts here detailed. No satisfactory explanation of so wide a divergence of statement offers itself at the present time. It might be suggested, 
however, that there is a possibility that the variety found off the Virginia coast, where Ryder made his observations, may show viviparity; but this is hardly likely to be the case.

Two possible explanations suggest themselves. Either Ryder dealt with another species, which he considered to be $F$. majalis, or he mistook for ovarian embryos some of the latter that had been eaten by the female under observation and had passed through the alimentary canal undigested. These fish have been observed to eat large numbers of their own eggs. The latter may pass through the alimentary canal without suffering the loss of anything but the gelatinous envelope. The embryos, however, that have passed through this experience are always dead. It seems scarcely likely that so excellent an observer as Ryder should have been led into a mistake of this sort; yet this appears to be the most likely explanation of the discrepancy.

\section{H. H. Newman}

\section{Austin, Texas}

\section{DEVICES FOR CHANGING THE TIMBRE OF MUSICAL INSTRUMENTS}

ENCLOSED is a rough sketch of a curious bridge, used on a Hindu stringed instrument, whose strings are picked. Fig. 1 shows top of bridge, and Fig. 2 an end view. There is a slight ridge near the lower side. Five grooves

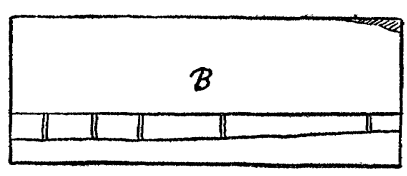

FIG. 1

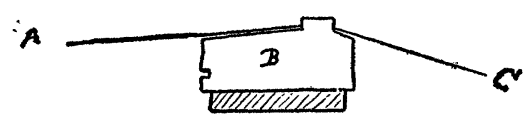

FIG. 2

are cut on this ridge for as many wire strings, whose relative position with the bridge is shown in Fig. 2. A represents the vibrating part of the string; $C$ the part attached to the tail piece. The vibrations of the string against the bridge produce a burring sound, which seems to be favored by the orientals.

In the "ti-tzu," a Chinese transverse flute, there is a hole, about the same size as the mouth-hole, half-way between the latter and the upper finger-hole, which is covered with a thin tissue, making a sympathetic drum, which changes the reedy timbre of the flute.

In a bamboo horn of the Filipinos, the lower end of the bamboo is split into strips about three eighths of an inch wide, producing a similar sound or result.

In Africa, the negro xylophones, marimbas, those that have a gourd resonator suspended beneath each sounding bar, have some of the gourds perforated and covered with a thin piece of cocoon, thus forming a sympathetic drum, and likewise changing the timbre of the instrument.

Would not such instruments have anything but a soothing effect on the nerves of our musicians? But it was not always so. Ac.cording to Mersenne, the beginning of the seventeenth century saw bands of four or five all playing on onion flutes, which met with great favor all through western Europe. This flute consisted of a straight wooden conical tube, with conical bore, the mouth hole on the side, and the open, small end of the tube covered with a thin skin of an onion; hence the name. The player sung or hummed the tune into the instrument, which resembled our modern kazoo or zobo, the change of timbre due to onion skin being pleasing at that period.

I have just come across the following article by A. C. Moule in the North China branch of the Royal Asiatic Society, 1908, page 78:

Rev. F. W. Galpin, of England, informs me that the device of covering a hole with membrane was not characteristic of the English recorder, as is sometimes stated; but that in the early part of the eighteenth century a transverse flute, called the voice flute, was produced in London with a membrane exactly like that of the $\mathrm{Ti}$ (the ti-tzu).

An advertisement of " a rare concert of four trumpets marine, never before heard in England," appeared in the London Gazette, of February 4, 1674. Some authors claim that 